\title{
Mouse Models of Food Allergy in the Pursuit of Novel Treatment Modalities
}

\author{
Johanna M. Smeekens ${ }^{1,2 \star}$ and Michael D. Kulis ${ }^{1,2}$ \\ ${ }^{1}$ Division of Allergy and Immunology, Department of Pediatrics, University of North Carolina School of Medicine, Chapel Hill, \\ NC, United States, ${ }^{2}$ University of North Carolina Food Allergy Initiative, Chapel Hill, NC, United States
}

The prevalence of IgE-mediated food allergies has increased dramatically in the past three decades, now affecting up to $10 \%$ of the US population. IgE-mediated food allergy is an immunologic disease, involving a variety of cells, including $B$ and $T$ cells, mast cells, basophils, ILC2s, and epithelial cells. Mouse models of food allergy mimic the overall immunologic processes known to exist in humans. Due to the limitations of invasive sampling of human tissue and the similarities of the human and mouse immune systems, comprehensive pathogenesis studies of food allergy have been performed in mouse models. Mouse models have been effective in elucidating the roles of non-oral routes of sensitization and identifying key cells and molecules involved in allergic sensitization. Furthermore, the development of novel therapeutic approaches for food allergy has been accelerated through the use of pre-clinical mouse models. Despite the groundbreaking findings stemming from research in mice, there are continued efforts to improve the translational utility of these models. Here, we highlight the achievements in

OPEN ACCESS

Edited by:

Ronald van Ree,

Amsterdam University Medical

Center, Netherlands

Reviewed by:

Jeffrey Michael Wilson,

University of Virginia, United States

*Correspondence:

Johanna M. Smeekens

smeeken3@email.unc.edu

Specialty section:

This article was submitted to

Food Allergy,

a section of the journal

Frontiers in Allergy

Received: 05 November 2021 Accepted: 23 November 2021

Published: 15 December 2021

Citation:

Smeekens JM and Kulis MD (2021) Mouse Models of Food Allergy in the Pursuit of Novel Treatment Modalities.

Front. Allergy 2:810067.

doi: 10.3389/falgy.2021.810067 understanding food allergy development and efforts to bring novel treatment approaches into clinical trials.

Keywords: food allergy, peanut allergy, mouse models, microbiome, immunotherapy

\section{INTRODUCTION}

IgE-mediated food allergies now affect an estimated $10 \%$ of the US population (1), which is a substantial increase from estimates generated over 20 years ago (2). The most common food allergies in the US are milk, egg, peanut, tree nuts, soy, wheat, fish, shellfish, and sesame. Reactions to accidental exposures are common and can be severe (3). Although fatal reactions brought on by allergic reactions to foods are exceedingly rare, they do happen (4). It is this uncertainty that causes anxiety and quality of life impairment in those with food allergies and their caregivers (5). Additionally, health care costs for food allergies in the US are approximately $\$ 25$ billion annually (6). Taken together, food allergy represents a significant public health concern.

Food allergies are an immunologic disease characterized by a Th2-driven response, resulting in the production of allergen-specific $\operatorname{IgE}(7)$. The current paradigm is that an initial sensitizing event occurs at an epithelial surface (i.e., skin, airway, gastrointestinal tract) where the food antigens come into contact with antigen presenting cells (APCs) (8). Once taken up by APCs, the antigens are processed and displayed through MHC class II molecules that allow activation of naïve T cells. The $\mathrm{T}$ cell fate is driven by the local cytokine milieu, now understood to be Th2-promoting cytokines from ILC2 cells and epithelial-derived cytokines such as TSLP, IL-33, and IL-25. In the presence of these pro-Th2 cytokines, the naïve T cells undergo differentiation into Th2-type cells, which then interact with B cells to cause class-switching into IgE-producing B cells (Figure 1). Ultimately, these $\mathrm{B}$ cells become long-lived plasma cells that may produce allergen-specific IgE for many years. 


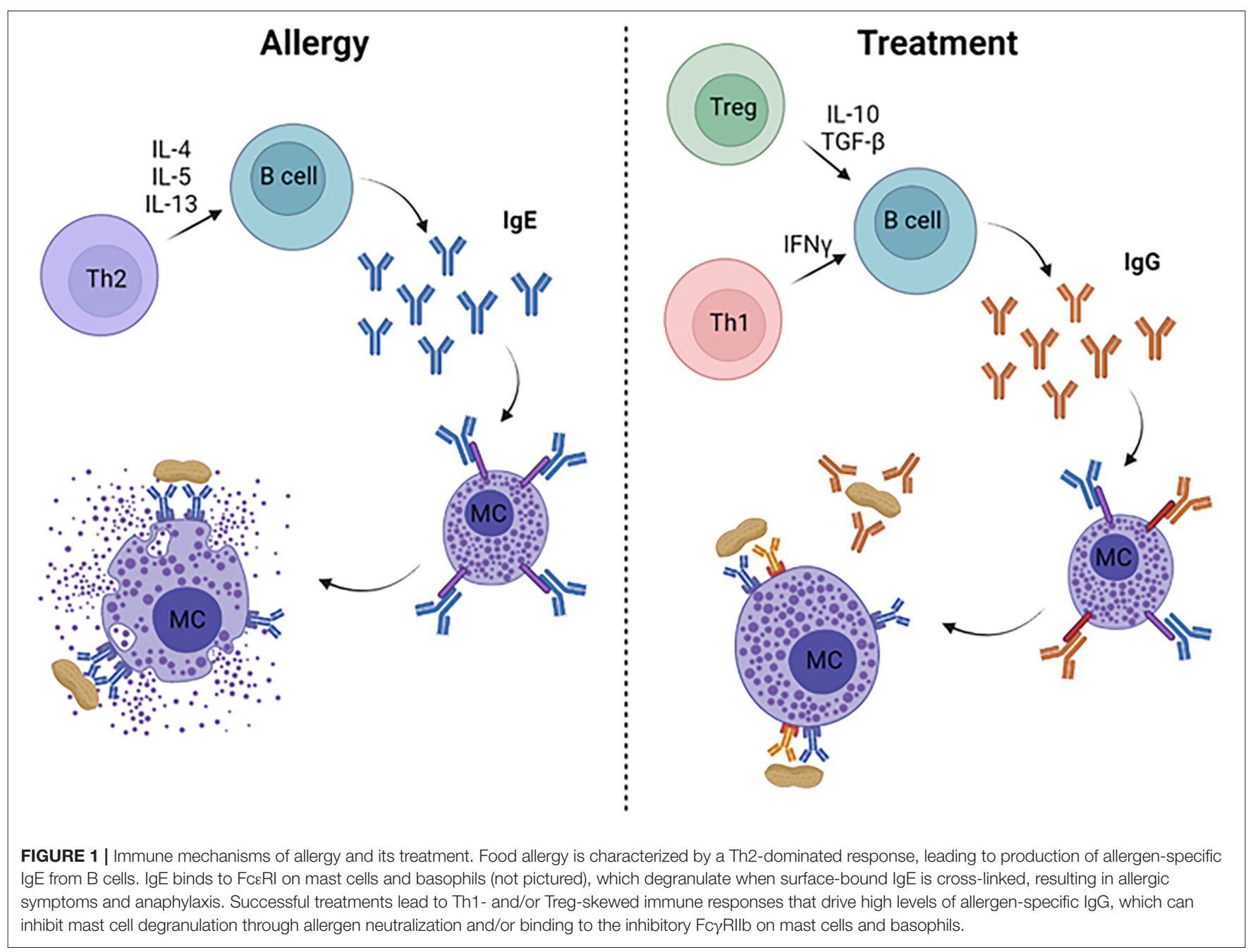

Once IgE is in circulation, it binds with high affinity to FceRI receptors on mast cells and basophils, priming these effector cells for allergic reactions. Specifically, subsequent exposures to allergenic foods will cross-link IgE on mast cells and basophils causing a signaling cascade that ends in degranulation and release of allergic mediators, such as histamine, leukotrienes, prostaglandins, and cytokines. These mediators result in the symptoms seen during an allergic reaction, including mild symptoms such as urticaria, emesis, diarrhea, edema, and more severe symptoms which include hypotension, neurologic compromise, and cardiovascular collapse.

Our understanding of the immunobiology of human food allergy has several limitations. For example, the sensitization phase in humans is extraordinarily difficult to study since patients typically present to an allergist after they've already experienced a food-induced reaction. This makes it impossible to pinpoint the sensitization event and what environmental factors may have led to the production of IgE. Other limitations in studying the human disease are the types of samples that can be acquired, often restricted to blood, saliva, urine, and stool. Conducting biopsies of skin and gastrointestinal (GI) tissue may be helpful, although these procedures are not routinely done on infants with food allergy. Our understanding of anaphylaxis is also limited because of the ethical constraints associated with intentionally causing moderate to severe allergic reactions. For these reasons, research has relied on animal models to better understand the pathophysiology of food allergy. In particular, mouse models have become a mainstay in food allergy research.

Mouse models of food allergy mimic key factors of the human disease (9). Upon sensitization to foods, mice will produce allergen-specific IgE, Th2-type cytokines, and will undergo mast cell-induced anaphylaxis upon food challenge. Importantly, we can also control the sensitizing events in mice, as well as the environmental and genetic factors that may drive food allergy. Collection of lymph nodes, spleens, and GI tissue, which are not studied in humans, has also furthered our understanding of food allergies. Finally, mouse models have shed light on mediators involved in anaphylaxis, such as platelet activating factor (PAF) (10). Based on an improved understanding of what causes food allergies and the molecules involved in anaphylaxis, we may be able to develop targeted prevention and therapeutic approaches. Indeed, mouse models have become an important pre-clinical 
tool to test novel therapies. In this review, we will focus on findings from mouse models that encompass the progress made in understanding immunologic mechanisms underlying food allergy and therapeutic strategies for their treatment.

\section{MODELING SENSITIZATION THROUGH VARIOUS EXPOSURE ROUTES}

\section{Oral and Systemic Sensitization}

As in humans, feeding food antigens orally to mice generally leads to the induction of oral tolerance (11). To circumvent tolerance mechanisms, researchers have turned to adjuvants to skew the immune response toward Th2. Classically, models of food allergy have relied on Th2-skewing adjuvants to induce sensitization. The most commonly used Th2-adjuvants are cholera toxin (CT), staphylococcal enterotoxin B (SEB), and aluminum hydroxide (alum). CT and SEB are co-administered with food proteins through the GI tract $(12,13)$, while allergens adsorbed to alum are delivered via intraperitoneal injection (14). The use of these adjuvants have led to models of allergy to peanut, milk, egg, tree nuts, shellfish, among others, in $\mathrm{BALB} / \mathrm{c}, \mathrm{C} 3 \mathrm{H} / \mathrm{HeJ}$ and $\mathrm{C} 57 \mathrm{BL} / 6$ mice, demonstrated by the production of allergen-specific IgE, Th2 cytokines and anaphylaxis upon food challenge (9). There are two strains of mice, CC027/GeniUnc and I14raF709, that can be enterally sensitized to food antigens in the absence of adjuvant. The CC027/GeniUnc mice come from the Collaborative Cross, and are an inbred strain resulting from funnel breeding of eight founder strains $(15,16)$. We have recently demonstrated that CC027/GeniUnc mice become allergic to peanut and walnut without a Th2-skewing adjuvant, and sensitization is associated with increased gut permeability, decreased fecal IgA and a unique gut microbiome (17). The Il4raF709 mice, in which the IL-4R $\alpha$ immunoreceptor tyrosine-based inhibitory motif is inactivated, can be sensitized to OVA in the absence of adjuvant (18). Interestingly, these mice also have increased gut permeability, suggesting that epithelial disruption may be a key driving force to orally-induced food allergy.

\section{Epicutaneous Sensitization}

As the paradigm for sensitization in humans has shifted to non-oral routes, animal models have been employed to help characterize these alternate routes of exposure. An impaired skin barrier in humans resulting from eczema or filaggrin mutations is associated with increased prevalence of food allergy. Mouse models have been developed that mimic eczema, including flaky tail (filaggrin deficient) mice (19) and in BALB/c mice with tape stripping (20), which removes the stratum corneum layer of the skin. Food antigens are applied to the impaired skin several times over the course of a few weeks, which leads to allergic sensitization. Importantly, in the flaky tail model, proteolytic allergens are co-administered with peanut to serve as an adjuvant. More recently, mice were sensitized to peanut through the skin in the absence of adjuvant or impaired skin, but milk or egg allergens administered on the skin did not lead to sensitization, indicating an inherent adjuvant property of peanut (21). Indeed, milk allergen applied to the skin with Ara h 2 led to induction of milk-specific IgE. Overall, data from these animal models provide convincing evidence that sensitization through the skin can lead to food allergy.

\section{Airway Sensitization}

Another potential non-oral route of exposure leading to sensitization is the airway, although human data is limited. Mouse models have demonstrated that sensitization to peanut can occur through the airway. Our group demonstrated that airway exposure to peanut plus house dust leads to the induction of peanut-specific IgE and anaphylaxis upon peanut challenge, indicating that house dust acts as an adjuvant to induce airway sensitization (22). Further studies of this model have demonstrated that the adjuvant activity is dependent upon MyD88, and co-administration of TLR signaling molecules, LPS, CpG, flagellin, PAM with peanut induces allergy (23). Using a different model, airway sensitization to peanut was demonstrated in the absence of an adjuvant. This model relied on airway exposure to peanut flour to produce peanut-specific IgE (24). Interestingly, both of these airway exposure models identified a role for Tfh cells in the induction of peanut allergy.

\section{Humanized Models}

Humanized mouse models of food allergy have also been reported. These models are attractive since they utilize human $\mathrm{B}$ and $\mathrm{T}$ cells, leading to the in vivo production of allergen-specific human IgE. In one model, CD34 ${ }^{+}$human hematopoietic stem cells were transferred into NSG mice and became successfully engrafted after 4 months (25). Human $\mathrm{CD} 45^{+}$cells were found in peripheral blood and tissues, with $\mathrm{CD} 4^{+} \mathrm{T}$ cells and $\mathrm{CD} 19^{+} \mathrm{B}$ cells found in the spleen. Furthermore, mast cells were identified in the intestinal mucosa. After engraftment, mice were orally exposed to peanut for 8 weeks, leading to production of peanutspecific IgE and anaphylaxis on peanut challenge. A second example of a humanized mouse model used PBMCs isolated from peripheral blood combined with peanut antigens to reconstitute NSG mice (26). Subsequently, mice were exposed to peanut for an additional 5 weeks to induce peanut-specific IgE production. These models highlight the possibility of studying food allergy in vivo using human cells.

\section{Limitations}

Despite the many advantages of mouse models, there are several limitations. One major difference between mouse and human sensitization is that anaphylaxis is not solely IgE-dependent in mice, due to the production of anaphylactic IgG1. This was definitively demonstrated in mice lacking IgE, which experienced anaphylaxis upon antigen challenge (27). Another key limitation is the cells involved in anaphylaxis differ in humans in mice. In humans, food-induced anaphylaxis is driven by mast cells and basophils, whereas in mice, mast cells, basophils, neutrophils and macrophages have all been shown to play an important role (2830). While humanized mouse models may more closely mimic the human disease, these models are currently hampered by the requirement of access to human blood, a substantially longer peanut allergy induction time, and higher costs. These limitations indicate further research is needed to develop optimal mouse models of food allergy. 


\section{THERAPEUTIC APPROACHES}

In addition to understanding how sensitization occurs, another powerful use of mouse models is developing novel therapies. Preclinical safety and efficacy studies in mice are necessary to bring treatments forward into Phase 1 clinical trials. In this section, we will review antigen-specific and non-specific therapeutic approaches and their mechanisms (Figure 1).

\section{Pre-clinical Therapies That Led to Clinical Trials}

There are several examples of therapies developed in mouse models that have reached clinical trials: epicutaneous immunotherapy (EPIT), mutated peanut allergens expressed in E. coli (EMP-123), and food allergy herbal formula (FAHF). EPIT for peanut allergy was initially tested in $\mathrm{BALB} / \mathrm{c}$ mice using a Viaskin peanut patch. This approach used electrostatically sprayed peanut protein on a patch applied to intact skin. Application of the patch creates a condensation chamber where peanut protein is solubilized and absorbed into the epidermis. In pre-clinical mouse studies, patch application led to an immunomodulatory effect highlighted by increased peanut-specific IgG2a $(31,32)$. Later studies found increased $\mathrm{LAP}^{+}$Tregs in the GI tract of mice treated with EPIT, indicating a skin-gut axis mechanism (33). EPIT was tested in humans, in Phase 1,2, and 3 clinical trials. These trials demonstrated an extremely favorable safety profile, although efficacy was limited to $35 \%$ of the study population after 1 year of treatment in the Phase 3 trial (34).

Another example is mutated Ara h 1, 2, and 3 expressed in E. coli. The premise of this treatment was to introduce mutations into the IgE binding epitopes of the major peanut allergens Ara $\mathrm{h} \mathrm{1,2}$, and 3 to reduce IgE binding capacity and mast cell degranulation, while retaining their ability to stimulate peanut-specific $\mathrm{T}$ cells. Expression in heat/phenolkilled $E$. coli was found to be an effective delivery system when given rectally in mice. In $\mathrm{C} 3 \mathrm{H} / \mathrm{HeJ}$ mice, this form of therapy led to increased peanut-specific IgG2a, decreased Th2-type cytokines, increased Tregs, and ultimately prevented reactions to peanut upon oral challenge (35). Finally, a Phase 1 clinical trial was undertaken in 10 peanut-allergic subjects to investigate the safety of this therapy. Unfortunately, the majority of subjects experienced symptoms, with half of the subjects having frequent adverse reactions, including $20 \%$ that experienced anaphylaxis, preventing completion of the protocol (36).

A non-antigen specific approach to treating food allergy arose from Traditional Chinese Medicine. The food allergy herbal formula (FAHF-2) is a blend of nine herbs given orally over the course of several weeks. In a $\mathrm{C} 3 \mathrm{H} / \mathrm{HeJ}$ model of peanut allergy, FAHF-2 blocked anaphylaxis and led to decreased peanutspecific IgE and Th2-type cytokines, with increased peanutspecific IgG2a and Th1-type cytokine production (37). FAHF-2 was tested for safety in a Phase 1 clinical trial and was found to be well-tolerated (38). In the Phase 2 trial, subjects took 10 tablets three times a day for 6 months, and there was no improvement in food challenge outcomes in the active or placebo arms, and no differences between arms in peanut-specific IgE, IgG4, IL-5, IL-13, IL-10, and IFN- $\gamma(39)$.

\section{Therapies Targeting T Cells}

There are several approaches that have shown promise in preclinical mouse models but have not yet made it into clinical trials. Since $\mathrm{T}$ cells are important in driving food allergy, therapies to suppress Th2 responses may be effective. One modality using peptides from the major egg allergen ovomucoid were shown to stimulate $\mathrm{T}$ cells, but lacked the ability to crosslink IgE, therefore rendering them unable to cause allergic reactions. When delivered orally for 4 weeks, this peptide-based immunotherapy induced Tregs and ovomucoid-specific IgA, while reducing ovomucoid-specific IgE, ultimately preventing anaphylaxis (40). Another approach used a whole peanut extract (WPE) linked to syngeneic splenocytes (SP) to induce antigenspecific immune tolerance (41). In a prophylactic model, i.v. administration of WPE-SP completely prevented production of peanut-specific IgE and led to minimal Th2 cytokine production. When applied in a therapeutic mouse model, two doses of WPESP led to significant suppression of anaphylaxis upon challenge, which was associated with decreased peanut-specific $\operatorname{IgE}$ and peanut-induced Th2 cytokines. Modulating T cell responses through the use of Th1-skewing adjuvants is another therapeutic approach. The TLR9 ligand, CpG, has been demonstrated to prevent and treat peanut allergy when given orally, intranasally, or by intraperitoneal injection. These studies all demonstrate the ability of $\mathrm{CpG}$ to induce IFN- $\gamma$ responses from peanut-specific $\mathrm{T}$ cells, with a subsequent increase in peanut-specific IgG2a (42-45). Finally, since virus-like particles (VLPs) are known to modulate $\mathrm{CD} 4^{+} \mathrm{T}$ cells, VLPs displaying food allergens may alter $\mathrm{T}$ cell responses leading to the production of allergen-specific IgG (46). Indeed, VLPs displaying Ara h 1 and 2 induced large quantities of allergen-specific IgG, which were protective against allergen challenge (47).

\section{Therapies Modulating the Gut Microbiome}

Studies have demonstrated the importance of the gut microbiome in food allergy in humans and mice (48). One study demonstrated that mice treated with antibiotics and then sensitized to peanut plus cholera toxin produced significantly higher peanutspecific IgE and IgG1 compared to non-antibiotic treated mice (49). Additionally, in germ-free mice, devoid of enteral microbes, oral food protein exposure led to elevated $\operatorname{IgE}$ and anaphylaxis upon oral challenge (49). Therefore, modulating the gut microbiome via the addition of protective bacteria or suppression of pathogenic bacteria may protect against various food allergies. Gnotobiotic mice reconstituted with Clostridia and sensitized with peanut plus cholera toxin had reduced peanut-specific IgE compared to germ-free controls. Furthermore, Clostridia induced IL-22 production in intestinal epithelial cells, which regulates intestinal permeability and allergen absorption (49). Another study by the same group demonstrated that transferring the microbiome from cow's milk allergic infants and subsequently sensitizing to the major milk allergen $\beta$-lactoglobulin (BLG) plus cholera toxin led to increased BLG-specific IgE, IgG1 and reactions on BLG 


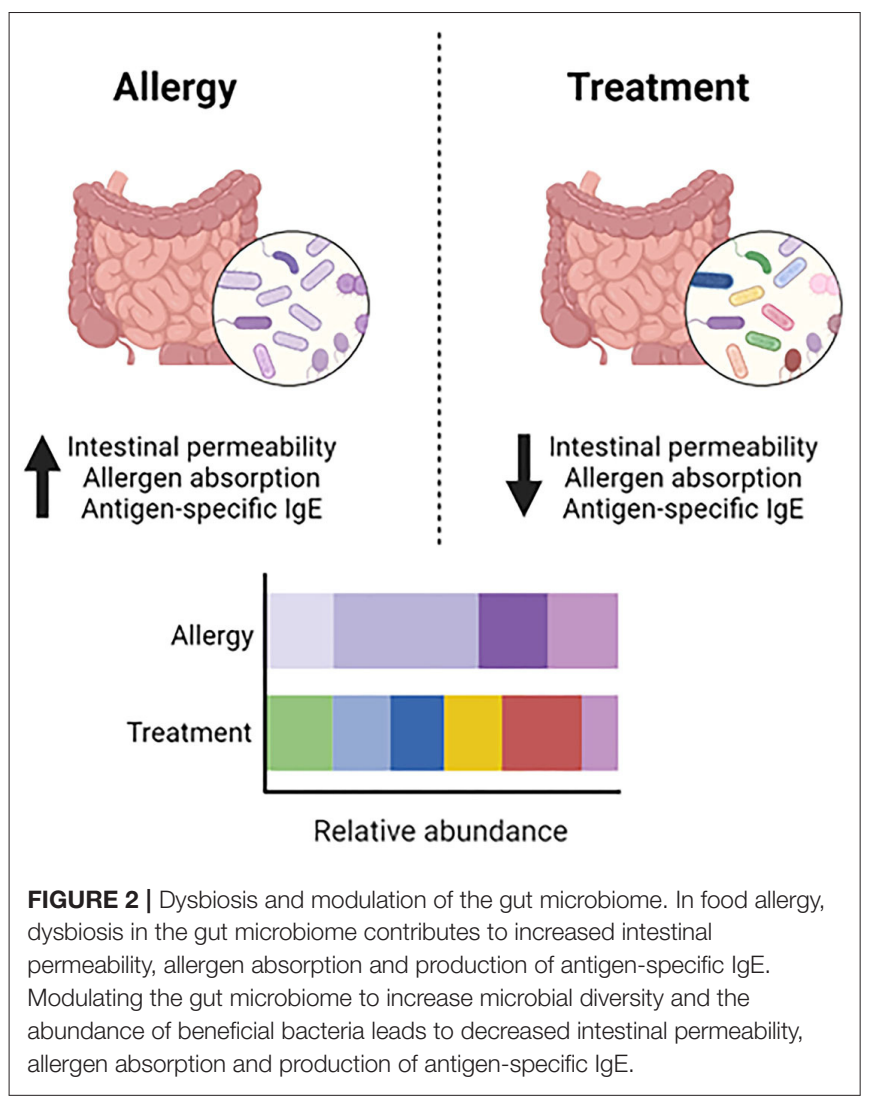

challenge, compared to mice that received microbiome transfers from healthy infants. Supplementation with one specific bacteria from the Clostridia family, Anaerostipes caccae, was found to be protective against food allergy, demonstrated by reduced BLG-specific IgE and IgG1 and reduced anaphylaxis on BLG challenge (50). Taken together, data from these studies indicate that manipulating the microbiome could have a therapeutic effect on food allergy (Figure 2).

\section{Therapies Targeting Siglecs on B Cells and Mast Cells}

Inhibitory Siglecs are ITIM-containing sialic acid-binding lectins expressed on a variety of immunologic leukocytes, including B cells and mast cells, making them attractive therapeutic targets. Siglec 2 (CD22) is an inhibitory Siglec on the surface of B cells that can be exploited to induce tolerance through its simultaneous engagement with the B cell receptor (51). An example of this approach for peanut allergy utilized liposomes co-displaying a CD22 ligand and Ara h 2 to successfully prevent production of Ara h 2-specific IgE, rendering the mice tolerant to this major peanut allergen (52). Siglec 3 (CD33) is displayed

\section{REFERENCES}

1. Gupta RS, Warren CM, Smith BM, Jiang J, Blumenstock JA, Davis MM, et al. Prevalence and severity of food allergies among US adults. JAMA Netw Open. (2019) 2:e185630. doi: 10.1001/jamanetworkopen.2018.5630 on the surface of mast cells and can be manipulated through co-ligation of IgE bound to FceRI to prevent degranulation. Indeed, in vivo studies demonstrated the utility of liposomes co-displaying anti-IgE and a CD33 ligand, which completely blocked anaphylaxis on challenge (53). Finally, Siglec 8 is found on human eosinophils and mast cells. Targeting Siglec 8 directly with antibodies shows some promise for inhibiting mast cell degranulation (54). However, liposomes co-displaying Siglec 8 and antigen, which recruits Siglec 8 to the IgE-FceRI complex, suppresses and desensitizes mast cells (55).

\section{DISCUSSION}

The standard of care for food allergy is avoidance of the offending food and ready access to epinephrine in case of accidental exposure. Although Palforzia, an oral immunotherapy (OIT) drug for the treatment of peanut allergy has been approved by the FDA, it will not be adopted by all food allergy patients due to the frequent allergic side effects, daily dosing and accessibility. Therefore, there is still an urgent need for improved food allergy therapies that will elicit fewer side effects, can be given less frequently, and induce tolerance. As described above, there are many promising candidates for therapies, however the few that have made it into clinical trials have not proven to be as effective as anticipated. These findings demonstrate a disconnect between mouse models of food allergy and human outcomes. In our opinion, identifying a mouse model that can accurately predict responses in humans would be a major breakthrough toward developing therapies. A successful clinical trial with an approach developed in mice will lead to understanding the underlying immunology and biomarkers that are correlated with successful outcomes. In summary, there are a plethora of promising therapeutic approaches being investigated to mitigate the food allergy epidemic.

\section{AUTHOR CONTRIBUTIONS}

MK and JS equally contributed to reviewing the literature and writing the manuscript. All authors contributed to the article and approved the submitted version.

\section{FUNDING}

MK is funded by the Department of Defense (W81XWH-16-10302 and W81XWH-21-1-0315) and JS was funded by a T32 through the National Institutes of Health (AI007062).

\section{ACKNOWLEDGMENTS}

Figures created with BioRender.com.

2. Sicherer SH, Munoz-Furlong A, Godbold JH, Sampson HA. US prevalence of self-reported peanut, tree nut, and sesame allergy: 11-year follow-up. J Allergy Clin Immunol. (2010) 125:1322-6. doi: 10.1016/j.jaci.2010.03.029

3. Fleischer DM, Perry TT, Atkins D, Wood RA, Burks AW, Jones $\mathrm{SM}$, et al. Allergic reactions to foods in preschool-aged children in a 
prospective observational food allergy study. Pediatrics. (2012) 130:e2532. doi: 10.1542/peds.2011-1762

4. Bock SA, Munoz-Furlong A, Sampson HA. Fatalities due to anaphylactic reactions to foods. J Allergy Clin Immunol. (2001) 107:191-3. doi: 10.1067/mai.2001.112031

5. Avery NJ, King RM, Knight S, Hourihane JO. Assessment of quality of life in children with peanut allergy. Pediatr Allergy Immunol. (2003) 14:37882. doi: 10.1034/j.1399-3038.2003.00072.x

6. Gupta R, Holdford D, Bilaver L, Dyer A, Holl JL, Meltzer D. The economic impact of childhood food allergy in the United States. JAMA Pediatr. (2013) 167:1026-31. doi: 10.1001/jamapediatrics.2013.2376

7. Tordesillas L, Berin MC, Sampson HA. Immunology of food allergy. Immunity. (2017) 47:32-50. doi: 10.1016/j.immuni.2017.07.004

8. Berin MC, Sampson HA. Mucosal immunology of food allergy. Curr Biol. (2013) 23:R389-400. doi: 10.1016/j.cub.2013.02.043

9. Schulke S, Albrecht M. Mouse models for food allergies: where do we stand? Cells. (2019) 8:546. doi: 10.3390/cells8060546

10. Arias $\mathrm{K}$, Baig $\mathrm{M}$, Colangelo $\mathrm{M}$, Chu $\mathrm{D}$, Walker $\mathrm{T}$, Goncharova $\mathrm{S}$, et al. Concurrent blockade of platelet-activating factor and histamine prevents lifethreatening peanut-induced anaphylactic reactions. J Allergy Clin Immunol. (2009) 124:307-14, 14 e1-2. doi: 10.1016/j.jaci.2009.03.012

11. Tordesillas L, Berin MC. Mechanisms of oral tolerance. Clin Rev Allergy Immunol. (2018) 55:107-17. doi: 10.1007/s12016-018-8680-5

12. Ganeshan K, Neilsen CV, Hadsaitong A, Schleimer RP, Luo X, Bryce PJ. Impairing oral tolerance promotes allergy and anaphylaxis: a new murine food allergy model. J Allergy Clin Immunol. (2009) 123:231-8 e4. doi: 10.1016/j.jaci.2008.10.011

13. Li XM, Serebrisky D, Lee SY, Huang CK, Bardina L, Schofield BH, et al. A murine model of peanut anaphylaxis: T- and B-cell responses to a major peanut allergen mimic human responses. J Allergy Clin Immunol. (2000) 106:150-8. doi: 10.1067/mai.2000.107395

14. Kulis $\mathrm{M}$, Pons $\mathrm{L}$, Burks $\mathrm{AW}$. In vivo and $\mathrm{T}$ cell cross-reactivity between walnut, cashew and peanut. Int Arch Allergy Immunol. (2009) 148:10917. doi: 10.1159/000155741

15. Orgel K, Smeekens JM, Ye P, Fotsch L, Guo R, Miller DR, et al. Genetic diversity between mouse strains allows identification of the CC027/GeniUnc strain as an orally reactive model of peanut allergy. J Allergy Clin Immunol. (2019) 143:1027-37 e7. doi: 10.1016/j.jaci.2018.10.009

16. Churchill GA, Airey DC, Allayee H, Angel JM, Attie AD, Beatty J, et al. The Collaborative Cross, a community resource for the genetic analysis of complex traits. Nat Genet. (2004) 36:1133-7. doi: 10.1038/ng1104-1133

17. Smeekens JM, Johnson-Weaver BT, Hinton AL, Azcarate-Peril MA, Moran TP, Immormino RM, et al. Fecal IgA, antigen absorption, and gut microbiome composition are associated with food antigen sensitization in genetically susceptible mice. Front Immunol. (2020) 11:599637. doi: 10.3389/fimmu.2020.599637

18. Burton OT, Darling AR, Zhou JS, Noval-Rivas M, Jones TG, Gurish MF, et al. Direct effects of IL-4 on mast cells drive their intestinal expansion and increase susceptibility to anaphylaxis in a murine model of food allergy. Mucosal Immunol. (2013) 6:740-50. doi: 10.1038/mi.2012.112

19. Walker MT, Green JE, Ferrie RP, Queener AM, Kaplan MH, Cook-Mills JM. Mechanism for initiation of food allergy: dependence on skin barrier mutations and environmental allergen costimulation. J Allergy Clin Immunol. (2018) 141:1711-25 e9. doi: 10.1016/j.jaci.2018.02.003

20. Strid J, Hourihane J, Kimber I, Callard R, Strobel S. Epicutaneous exposure to peanut protein prevents oral tolerance and enhances allergic sensitization. Clin Exp Allergy. (2005) 35:757-66. doi: 10.1111/j.1365-2222.2005.02260.x

21. Tordesillas L, Goswami R, Benede S, Grishina G, Dunkin D, Jarvinen KM, et al. Skin exposure promotes a Th2-dependent sensitization to peanut allergens. J Clin Invest. (2014) 124:4965-75. doi: 10.1172/JCI75660

22. Smeekens JM, Immormino RM, Balogh PA, Randell SH, Kulis MD, Moran TP. Indoor dust acts as an adjuvant to promote sensitization to peanut through the airway. Clin Exp Allergy. (2019) 49:1500-11. doi: 10.1111/cea.13486

23. Smeekens JM, Immormino RM, Kulis MD, Moran TP. Timing of exposure to environmental adjuvants is critical to mitigate peanut allergy. J Allergy Clin Immunol. (2021) 147:387-90 e4. doi: 10.1016/j.jaci.2020.09.011

24. Dolence JJ, Kobayashi T, Iijima K, Krempski J, Drake LY, Dent AL, et al. Airway exposure initiates peanut allergy by involving the IL-1 pathway and
T follicular helper cells in mice. J Allergy Clin Immunol. (2018) 142:1144-58 e8. doi: 10.1016/j.jaci.2017.11.020

25. Burton OT, Stranks AJ, Tamayo JM, Koleoglou KJ, Schwartz LB, Oettgen HC. A humanized mouse model of anaphylactic peanut allergy. $J$ Allergy Clin Immunol. (2017) 139:314-22 e9. doi: 10.1016/j.jaci.2016. 04.034

26. Pagovich OE, Wang B, Chiuchiolo MJ, Kaminsky SM, Sondhi D, Jose CL, et al. Anti-hIgE gene therapy of peanut-induced anaphylaxis in a humanized murine model of peanut allergy. J Allergy Clin Immunol. (2016) 138:1652-62 e7. doi: 10.1016/j.jaci.2016.03.053

27. Oettgen HC, Martin TR, Wynshaw-Boris A, Deng C, Drazen JM, Leder P. Active anaphylaxis in IgE-deficient mice. Nature. (1994) 370:36770. doi: $10.1038 / 370367 \mathrm{a} 0$

28. Jonsson F, Mancardi DA, Kita Y, Karasuyama H, Iannascoli B, Van Rooijen N, et al. Mouse and human neutrophils induce anaphylaxis. J Clin Invest. (2011) 121:1484-96. doi: 10.1172/JCI45232

29. Escribese MM, Rosace D, Chivato T, Fernandez TD, Corbi AL, Barber D. Alternative anaphylactic routes: the potential role of macrophages. Front Immunol. (2017) 8:515. doi: 10.3389/fimmu.2017. 00515

30. Finkelman FD. Anaphylaxis: lessons from mouse models. J Allergy Clin Immunol. (2007) 120:506-15; quiz 16-7. doi: 10.1016/j.jaci.2007. 07.033

31. Mondoulet L, Dioszeghy V, Ligouis M, Dhelft V, Dupont C, Benhamou PH. Epicutaneous immunotherapy on intact skin using a new delivery system in a murine model of allergy. Clin Exp Allergy. (2010) 40:65967. doi: 10.1111/j.1365-2222.2009.03430.x

32. Dioszeghy V, Mondoulet L, Dhelft V, Ligouis M, Puteaux E, Benhamou $\mathrm{PH}$, et al. Epicutaneous immunotherapy results in rapid allergen uptake by dendritic cells through intact skin and downregulates the allergen-specific response in sensitized mice. J Immunol. (2011) 186:5629-37. doi: 10.4049/jimmunol.1003134

33. Tordesillas L, Mondoulet L, Blazquez AB, Benhamou PH, Sampson HA, Berin MC. Epicutaneous immunotherapy induces gastrointestinal LAP+ regulatory $\mathrm{T}$ cells and prevents food-induced anaphylaxis. J Allergy Clin Immunol. (2017) 139:189-201 e4. doi: 10.1016/j.jaci.2016.03.057

34. Fleischer DM, Greenhawt M, Sussman G, Begin P, Nowak-Wegrzyn A, Petroni D, et al. Effect of epicutaneous immunotherapy vs placebo on reaction to peanut protein ingestion among children with peanut allergy: the PEPITES randomized clinical trial. JAMA. (2019) 321:94655. doi: 10.1001/jama.2019.1113

35. Li XM, Srivastava K, Grishin A, Huang CK, Schofield B, Burks W, et al. Persistent protective effect of heat-killed Escherichia coli producing "engineered," recombinant peanut proteins in a murine model of peanut allergy. J Allergy Clin Immunol. (2003) 112:159-67. doi: 10.1067/mai.2003.1622

36. Wood RA, Sicherer SH, Burks AW, Grishin A, Henning AK, Lindblad R, et al. A phase 1 study of heat/phenol-killed, E. coli-encapsulated, recombinant modified peanut proteins Ara h 1, Ara h 2, and Ara h 3 (EMP-123) for the treatment of peanut allergy. Allergy. (2013) 68:803-8. doi: 10.1111/all. 12158

37. Srivastava KD, Kattan JD, Zou ZM, Li JH, Zhang L, Wallenstein $\mathrm{S}$, et al. The Chinese herbal medicine formula FAHF-2 completely blocks anaphylactic reactions in a murine model of peanut allergy. J Allergy Clin Immunol. (2005) 115:171-8. doi: 10.1016/j.jaci.2004. 10.003

38. Patil SP, Wang J, Song Y, Noone S, Yang N, Wallenstein S, et al. Clinical safety of Food Allergy Herbal Formula-2 (FAHF-2) and inhibitory effect on basophils from patients with food allergy: Extended phase I study. J Allergy Clin Immunol. (2011) 128:1259-65 e2. doi: 10.1016/j.jaci.2011. 06.015

39. Wang J, Jones SM, Pongracic JA, Song Y, Yang N, Sicherer SH, et al. Safety, clinical, and immunologic efficacy of a Chinese herbal medicine (Food Allergy Herbal Formula-2) for food allergy. J Allergy Clin Immunol. (2015) 136:962-70 e1. doi: 10.1016/j.jaci.2015.04.029

40. Rupa P, Mine Y. Oral immunotherapy with immunodominant T-cell epitope peptides alleviates allergic reactions in a Balb/c mouse model of egg allergy. Allergy. (2012) 67:74-82. doi: 10.1111/j.1398-9995.2011.02724.x 
41. Smarr CB, Hsu CL, Byrne AJ, Miller SD, Bryce PJ. Antigen-fixed leukocytes tolerize Th2 responses in mouse models of allergy. J Immunol. (2011) 187:5090-8. doi: 10.4049/jimmunol.1100608

42. Srivastava KD, Siefert A, Fahmy TM, Caplan MJ, Li XM, Sampson HA. Investigation of peanut oral immunotherapy with $\mathrm{CpG}$ /peanut nanoparticles in a murine model of peanut allergy. J Allergy Clin Immunol. (2016) 138:53643 e4. doi: 10.1016/j.jaci.2016.01.047

43. Kulis M, Gorentla B, Burks AW, Zhong XP. Type B CpG oligodeoxynucleotides induce Th1 responses to peanut antigens: modulation of sensitization and utility in a truncated immunotherapy regimen in mice. Mol Nutr Food Res. (2013) 57:906-15. doi: 10.1002/mnfr.201200410

44. Johnson-Weaver BT, Sempowski GD, Staats HF. Nasal peanut+ CpG immunotherapy enhances peanut-specific IFN-gamma in Th2 cells and IL-10 in non-Th2 cells in mice. Allergy. (2019) 74:2220-3. doi: 10.1111/all.13738

45. Zhu FG, Kandimalla ER, Yu D, Agrawal S. Oral administration of a synthetic agonist of Toll-like receptor 9 potently modulates peanut-induced allergy in mice. J Allergy Clin Immunol. (2007) 120:631-7. doi: 10.1016/j.jaci.2007.05.015

46. Braun M, Jandus C, Maurer P, Hammann-Haenni A, Schwarz K, Bachmann MF, et al. Virus-like particles induce robust human T-helper cell responses. Eur J Immunol. (2012) 42:330-40. doi: 10.1002/eji.201142064

47. Storni F, Zeltins A, Balke I, Heath MD, Kramer MF, Skinner MA, et al. Vaccine against peanut allergy based on engineered virus-like particles displaying single major peanut allergens. J Allergy Clin Immunol. (2020) 145:1240-53 e3. doi: 10.1016/j.jaci.2019.12.007

48. Blazquez AB, Berin MC. Microbiome and food allergy. Transl Res. (2017) 179:199-203. doi: 10.1016/j.trsl.2016.09.003

49. Stefka AT, Feehley T, Tripathi P, Qiu J, McCoy K, Mazmanian SK, et al. Commensal bacteria protect against food allergen sensitization. Proc Natl Acad Sci USA. (2014) 111:13145-50. doi: 10.1073/pnas.14120 08111

50. Feehley T, Plunkett CH, Bao R, Choi Hong SM, Culleen E, Belda-Ferre P, et al. Healthy infants harbor intestinal bacteria that protect against food allergy. Nat Med. (2019) 25:448-53. doi: 10.1038/s41591-018-0324-z

51. Macauley MS, Pfrengle F, Rademacher C, Nycholat CM, Gale AJ, von Drygalski A, et al. Antigenic liposomes displaying CD22 ligands induce antigen-specific B cell apoptosis. J Clin Invest. (2013) 123:307483. doi: 10.1172/JCI69187
52. Orgel KA, Duan S, Wright BL, Maleki SJ, Wolf JC, Vickery BP, et al. Exploiting CD22 on antigen-specific B cells to prevent allergy to the major peanut allergen Ara h 2. J Allergy Clin Immunol. (2017) 139:366-9 e2. doi: 10.1016/j.jaci.2016.06.053

53. Duan S, Koziol-White CJ, Jester WF Jr., Smith SA, Nycholat CM, Macauley MS, et al. CD33 recruitment inhibits IgE-mediated anaphylaxis and desensitizes mast cells to allergen. J Clin Invest. (2019) 129:1387401. doi: 10.1172/JCI125456

54. Yokoi H, Choi OH, Hubbard W, Lee HS, Canning BJ, Lee HH, et al. Inhibition of FcepsilonRI-dependent mediator release and calcium flux from human mast cells by sialic acid-binding immunoglobulin-like lectin 8 engagement. J Allergy Clin Immunol. (2008) 121:499-505 e1. doi: 10.1016/j.jaci.2007. 10.004

55. Duan S, Arlian BM, Nycholat CM, Wei Y, Tateno H, Smith SA, et al. Nanoparticles displaying allergen and Siglec-8 ligands suppress IgEFcepsilonRI-mediated anaphylaxis and desensitize mast cells to subsequent antigen challenge. J Immunol. (2021) 206:2290-300. doi: 10.4049/jimmunol. 1901212

Conflict of Interest: The authors declare that the research was conducted in the absence of any commercial or financial relationships that could be construed as a potential conflict of interest.

Publisher's Note: All claims expressed in this article are solely those of the authors and do not necessarily represent those of their affiliated organizations, or those of the publisher, the editors and the reviewers. Any product that may be evaluated in this article, or claim that may be made by its manufacturer, is not guaranteed or endorsed by the publisher.

Copyright (C) 2021 Smeekens and Kulis. This is an open-access article distributed under the terms of the Creative Commons Attribution License (CC BY). The use, distribution or reproduction in other forums is permitted, provided the original author(s) and the copyright owner(s) are credited and that the original publication in this journal is cited, in accordance with accepted academic practice. No use, distribution or reproduction is permitted which does not comply with these terms. 